\title{
FIRST RESULTS OF TIME SERIES ANALYSIS OF THE PERMANENT GNSS OBSERVATIONS AT POLISH EPN STATIONS USING GIPSYX SOFTWARE
}

\author{
Adam ŁYSZKOWICZ1 ${ }^{1}$, Renata PELC-MIECZKOWSKA ${ }^{2}$, \\ Anna BERNATOWICZ ${ }^{3}$, Stepan SAVCHUK ${ }^{1}$ \\ ${ }^{1}$ Military University of Aviation, Dęblin, Poland \\ 2 University of Warmia and Mazury, Olsztyn, Poland \\ ${ }^{3}$ Koszalin University of Technology, Koszlin, Poland \\ e-mails: a.lyszkowicz@,law.mil.pl, renata.pelcmieczkowska@gmail.com, \\ anna.bernatowicz@,tu.koszalin.pl, s.savchuk@,law.mil.p1
}

\begin{abstract}
The aim of this work is to explore, for the first time in Poland, the possibility of determining Earth's crust movements from permanent observations at selected permanent stations using the GipsyX software for a period of 8 years (2011-2018) in the ITRF2014 reference frame. The data used in this work are from 15 Aktywna Sieć Geodezyjna (ASG)EUPOS stations from 2011 to 2018, which are also European Permanent Network (EPN) stations. The stations Borowa Góra, Borowiec, Józefosław, Lamkówko, and Wroclaw are also International Global Navigation Satellite Systems (GNSS) Service (IGS) stations. Daily data, rinex files, for these stations have been made available for this work by the Main Office of Surveying and Cartography. The calculations were made using the GipsyX software in the ITRF14 reference frame. The tests performed have shown that daily solutions from 8-yearlong time series give secular trends with an accuracy of $0.01 \mathrm{~mm} / \mathrm{yr}$. Our results suggest that there are small differences in horizontal and vertical velocities and in the accuracy estimated between our and EPN solutions. At some stations, for example, Łódź, the differences are much larger. The impact of additional GNSS observations on the accuracy of determination of horizontal and vertical movements of the Earth's crust shows a submillimeter accuracy in computed coordinates of stations even at a relatively small time interval. It means that multiGNSS Precise Point Positioning (PPP) processing can be used in the future for the estimation of geodynamic processes.
\end{abstract}

Keywords: vertical crustal movements, PPP method, GNSS time series analysis

\section{INTRODUCTION}

The horizontal and vertical movements of the Earth's crust are caused by geophysical processes as well as processes resulting from human activity (Krakiwsky, 1986). Geophysical processes are movements of the Earth's crust caused by external and internal factors such as the formation and disappearing of land planes, changes in the amount of water in reservoirs, sedimentation, erosion, increasing the load on the crust as a result of mountainous movements, etc. (Gubler and Kahle, 1985; Zhang et al, 2015; Teatini et al., 2011). Artificial processes that cause horizontal and vertical movements of the Earth's crust are associated with 
human activities such as mines, dehumidification or irrigation of the sites, as well as the testing of nuclear weapons (Teatini et al., 2011; Zhang et al., 2015; Torge, 2001; Lindberg, 2014).

Knowledge of the Earth's crust movement model is essential in geophysics to explain the processes taking place on and inside the Earth and in surveying to create a kinematic vertical system (Gubler, 1984) and to properly manage subsequent ETRS89 implementations within the country (Pelzer and Niemeier, 1984).

Until recently, the vertical movements of the Earth's crust were determined from successive precise leveling campaigns. The literature on this subject is quite rich. For example, see the following list of works: Sandford (1978), Saaranen and Mäkinen (2002), Wyrzykowski (1987), Niewiarowski (1961), Wyrzykowski (1985).

The movements thus computed were relative, that is, relative to the average sea level of the selected mareograph or mareographs, and usually covered the area of the country concerned. In Poland, the first computation of vertical movements of the Earth's crust was made between 1961 and 1985 (see Wyrzykowski, 1987).

The best model from the repeated leveling data was computed in 2005 (Kowalczyk, 2005). This model was computed from a comparison of the results of the third (1974-1982) and fourth campaigns (1997-2003) of precise leveling. As a result of adjustment of the network of height differences of the leveling lines, assuming the nodal benchmark in Władysławowo as a fixed, relative movement (land uplift) was obtained in Poland. The final model of vertical movements was obtained by interpolating the values of vertical movements at a geographic grid $20^{\prime} \times 20^{\prime}$ by a collocation method. This model has an accuracy of $\pm 0.05 \mathrm{~mm} / \mathrm{yr}$ (see Kowalczyk, 2006).

With the advent of satellite navigation systems (Murra et al., 2020) and the emergence of a network of permanent Global Positioning System (GPS) stations (Zogg, 2002; Segall, 1997), the possibility of determining horizontal and vertical movements from the analysis of the time series of Global Navigation Satellite Systems (GNSS) observations has emerged (Feng and Chen, 2019; Szolucha et al., 2018). GPS processing software is generally either based on double difference observations (or relative positioning) (Kowalczyk, 2017) or Precise Point Positioning (PPP) solution (Ye, 2002; Dong, 1989).

In the period of 3 years from 2008 to 2011 , about 100 permanent stations were calculated in the International Terrestrial Reference Frame 2005 (ITRF2005) reference frame using the network positioning software CATREF (Altamimi et al, 2007). The first accurate computation of the vertical movements from GPS observations in the area of Poland was realized in 2012 (Kontny, 2012). The computed model indicates small vertical movements in the range from +1 to $-1 \mathrm{~mm} / \mathrm{yr}$ in the dominating area of Poland. Bigger subsidence is shown in areas influenced by stations with anomalous values of vertical velocities: GWWL (Gorzow Wielkopolski) - $4.4 \mathrm{~mm} / \mathrm{yr}$, LELO (Lelow) -4.9 mm/yr, LODZ (Łódź) $-2.4 \mathrm{~mm} / \mathrm{yr}$, SIDZ (Sieradz) $-2.7 \mathrm{~mm} / \mathrm{yr}$, SWKI (Suwalki) $-2.1 \mathrm{~mm} / \mathrm{yr}$. Mean errors of these velocities do not accede to the level of $\pm 0.5- \pm 0.8 \mathrm{~mm} / \mathrm{yr}$.

In 2015, Kowalczyk et al. (2015) used data from 343 stations of the Aktywna Sieć Geodezyjna (ASG) network (Zieliński et al., 1998) for the period 2008-2013 (5 years) and computed relative vertical crustal movements in the area of Poland. They were based on ASG-EUPOS stations whose positions were calculated by Bernese GPS Software 5.0 network positioning software. Then the time series of height differences between the neighboring stations were created and a linear trend was calculated. This trend is from 3 to $-7.5 \mathrm{~mm} / \mathrm{yr}$ 
and its accuracy does not accede $2.5 \mathrm{~mm} / \mathrm{yr}$. The largest values of the trend are visible in the areas of Krakow, Warsaw, Silesia, and in the area of north-eastern Poland.

The first work on the use of the PPP method to determine the vertical movements of the Earth's crust in Poland was carried out in 2017 (Kowalczyk, 2017). The authors used daily time series from the PPP solutions processed by Nevada Geodetic Laboratory (NGL) from 55 permanent stations located in Poland, Lithuania, and Latvia. The calculation resulted in the land uplift from -1.0 to $1.5 \mathrm{~mm} / \mathrm{yr}$ with an accuracy from \pm 0.1 to $\pm 0.3 \mathrm{~mm} / \mathrm{yr}$.

According to the literature review presented above, the issue of modern horizontal and vertical movements of the Earth's crust in Poland is a very complex problem and their correct solution depends on many factors. First of all, the PPP method is currently recommended. According to the literature review, generally speaking, attempts to determine station movements from permanent GNSS observations have a very short period (3 years); station positions were calculated from network solutions (correlated results) and determined in previous (less-accurate) implementations of the ITRF reference frame.

The aim of this work is to explore the possibility of determining Earth's crust movements in Poland for the first time from permanent observations at selected stations of the ASG-EUPOS network using the GipsyX software for a period of 8 years (2011-2018) in the ITRF2014 reference frame. Calculations will be made in several variants to assess the impact of time series multiplicity on the parameters to be determined, assess the consistency of the results obtained by different calculation groups, as well as examine the impact of the software used to analyze time series on the obtained results. The final issue to be addressed in this publication is the assessment of the benefits of the so-called multi-GNSS observation strategy (Guo et al., 2017).

The obtained results shall be compared with the results of the European Permanent Network (EPN) solution. The aim of the work is also to focus on the study of how the use of additional satellite observations (GLONASS, Galileo) will not affect the accuracy of the computed Earth's crust movements.

The experience gained in this work will be used to determine the crust movements in Poland from observations at all stations of the ASG-EUPOS network.

\section{NETWORK AND DATA DESCRIPTION}

In 2008, the Head Office of Geodesy and Cartography launched the multifunctional ASGEUPOS precision satellite positioning system. As a part of this system, 75 new GNSS reference stations were installed in Poland. Also, 22 existing stations managed by universities, research units, public administrations, and private companies, as well as around 30 border stations from neighboring countries, have been integrated into the system to ensure uniform coverage of reference stations across the country (Bosy et al., 2010).

Presently, the network consists of 127 reference stations located in the Polish territory (Figure 2 1). The network created on these stations fulfills EUPOS requirements such as regular distribution of the stations, mean distances between neighboring stations $(70 \mathrm{~km})$, and assimilation of all existing Polish EPN and International GNSS Service (IGS) stations (Ryczywolski et al., 2008). Reference stations are mainly located on the buildings of public institutions.

Locations were selected by the verification results that concern the possibility of installing the GNSS antenna (by analyzing the observation conditions of GNSS satellites) and the placement of a 19-inch rack with modules: receiving, primary and emergency power, remote 
control and communication, as well as the possibility to establish communication connections (Ryczywolski et al., 2010).

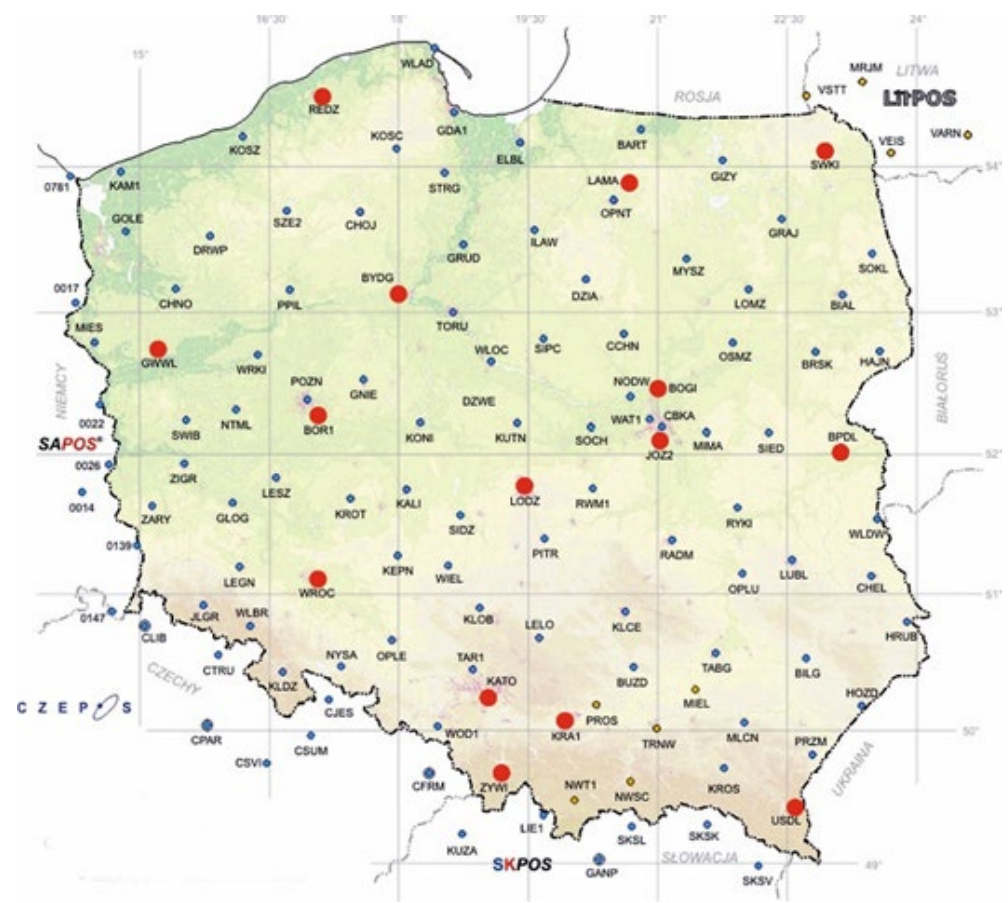

Figure 1. Location of ASG-EUPOS stations and 15 selected points (red circles) included in the computations

The data used in this work is derived from the observations between 2011 and 2018 at 15 ASG-EUPOS stations (see Figure 1), which are also EPN stations. The stations Borowa Góra, Borowiec, Józefosław, Lamkówko, and Wroclaw are also IGS stations. This means that these stations offer a great opportunity to check our results as very accurate results of these stations are published by EUREF and IGS. For more details on these stations, see Bosy et al. (2015). Daily data, rinex files, for these stations have been made available for this work by the Main Office of Surveying and Cartography.

\section{PROCESSING STRATEGY}

A large number of scientific papers are dedicated to the application of GNSS technologies in geodynamic research (e.g. Bock et al., 1993; Zumberge et al., 1997; Blewitt, 2011). However, the use of the PPP method in the research of geodynamic processes is not common, but there are some perspectives of PPP in this direction, especially in the availability and use of appropriate software. Since the beginning of the PPP method (Zumberge et al., 1997), research on the convergence time of the solution to achieve results with accuracy appropriate for different tasks has been carried out (Yi et al., 2017). According to the results of this research, decimeter accuracy of the PPP method can be achieved during the first hour of continuous observations in a static mode, and the results of processing daily observations achieve a centimeter and close to millimeter accuracy. Convergence time in PPP can be significantly reduced with an increase in the number of constantly observed satellites, as well as using a priori information (PPP with Ambiguity Resolution) (Yi et al., 2017).

The most important factor limiting the accuracy of PPP is the short-term instability of frequency standards on board GNSS satellites, which leads to poorly predicted behavior of satellite clock corrections (e.g. Villiger and Dach, 2017). Therefore, the satellite clock correction cannot be predicted as accurately as it could be estimated. The launch of new 
satellites with passive hydrogen masers (Galileo) improves the situation, but does not eliminate this issue.

Therefore, the PPP method, even with refined ephemeris time information, will not correspond to the phase relative positioning method in terms of accuracy. A possible modern solution to this issue is to use estimates of the instability of satellite clock corrections, as well as ephemeris information obtained from a network of global GNSS stations.

This technology is similar to that used in the networks of terrestrial reference stations (RTK or RTN). It lies in PPP estimates' extension by using precise undifferenced atmospheric corrections and satellite clock corrections from a network of permanent GNSS stations. But it must be taken into account that the use of this technology is possible only if such corrections are regularly determined and are available to the user and the related software.

At the present stage of development of related GNSS technologies, the PPP method is associated with the refinement of ephemeris time information, ionospheric and tropospheric models, earth orientation parameters, etc. and by its characteristics, reaches the accuracy of relative positioning method (Zumberge et al., 1997). Millimeter accuracy of the PPP method can be achieved based on the results of daily observations. Based on the experience of applying the PPP method in geodynamic research, it can be emphasized that this method has an undeniable advantage over the relative positioning method in the analysis of velocities and amplitudes of seismic waves. However, the main (for this research) perspective of the PPP method over the relative positioning method is the absence of dependence on the accuracy of determining the position of the points on the Earth's surface on the distances between them and the autonomy of determining their spatial position, which allows, in addition to local, to study the general (regional) movements of the Earth's surface.

\subsection{GPS and GSNN data processing}

In this work, stations' positions have been calculated using GipsyX software developed by the Jet Propulsion Laboratory (JPL) in 2017 (Lichten et al., 1996). This program has a basic gd2p.pl module that works with single receiver data giving a static point positioning in a standard stacov coordinate file. The GNSS data were processed using the PPP technique (Chen and Yang, 2011) in a static mode. Dual-frequency phase observations were used together with JPL final precise orbits (sp3 files) and clocks (clk files) (Kouba, 2003). The ionosphere-free linear combination was used to reduce the ionospheric error, while the tropospheric zenith delay was estimated. The processing interval was $30^{\text {s }}$ and the elevation mask $10^{\circ}$.

The GNSS Products (antenna models, final ephemerides and clocks, and Earth orientation parameters) were downloaded automatically from the JPL server: (https://sideshow.jpl.nasa.gov/pub/JPL GNSS Products/Final). From June 2018, thanks to third reprocessing campaign orbits and clocks, products in JPL_GNSS_Products/Final are IGS14 reference frame. This prevents the need to convert coordinates between reference systems. To calculate the dry and wet components of Zenith Tropospheric Delay, a Global Mapping Function was used.

One of the primary advantages of using this software is a single coordinate system on which the files are based. From the last reprocessing of products in 2011, all of the position results are given in the IGS08 coordinate system, and the time series is thus free of any offsets or jumps due to changes in the reference frame. Furthermore, it is possible to increase the accuracy of the coordinate calculus using a higher rate of sampling of the clock file (as short as 5 seconds), which is an advantage in short time series or kinematic studies. 
To estimate the position of a GNSS station for a daily observational file, the gd2e.py module is used. As an input parameter, rinex file path should be given. The script operates in PPP mode as the default one, while -rnxFile argument is called and then ocean load modeling is off what is appropriate for future geodynamics studies. The GNSS Products (antenna models, final ephemerides and clocks, etc.) are downloaded from the JPL server, while gd2e is running by default. To get the covariance matrix, -gdCov argument is required. Subsequently, there is a set of scripts (netSplit. py, staFit.py, staSeries.py, staBreak.py, staEdit.py) for creating, fitting, and computing of time series for the station; breaks and outliers detection; fitting seasonal terms; and finally; for station velocities determination as well as its sigma as a precision indicator. As an input, a smoothFinal.gdc ov file is required for each day.

The work consists of three variants of time series calculations from permanent GPS and one calculation of GNSS observations at selected ASG-EUPOS stations. In the first variant, only one day per month was processed and in the other variants, each day was processed. In all variants, all the options and software used in processing are exactly the same.

In the first case time series of GPS, observations were created from the observations on the 15th day of each month as described in Herring (2003) and calculated at the University of Technology in Koszalin (UTK). These calculations resulted in a time series from 96 to 88 observations.

The second case version consists of the time series computed for all daily GPS observations of a given station and calculated at the University of Warmia and Mazury (UWM). It gives a series of 2833 elements (see Figure 2).

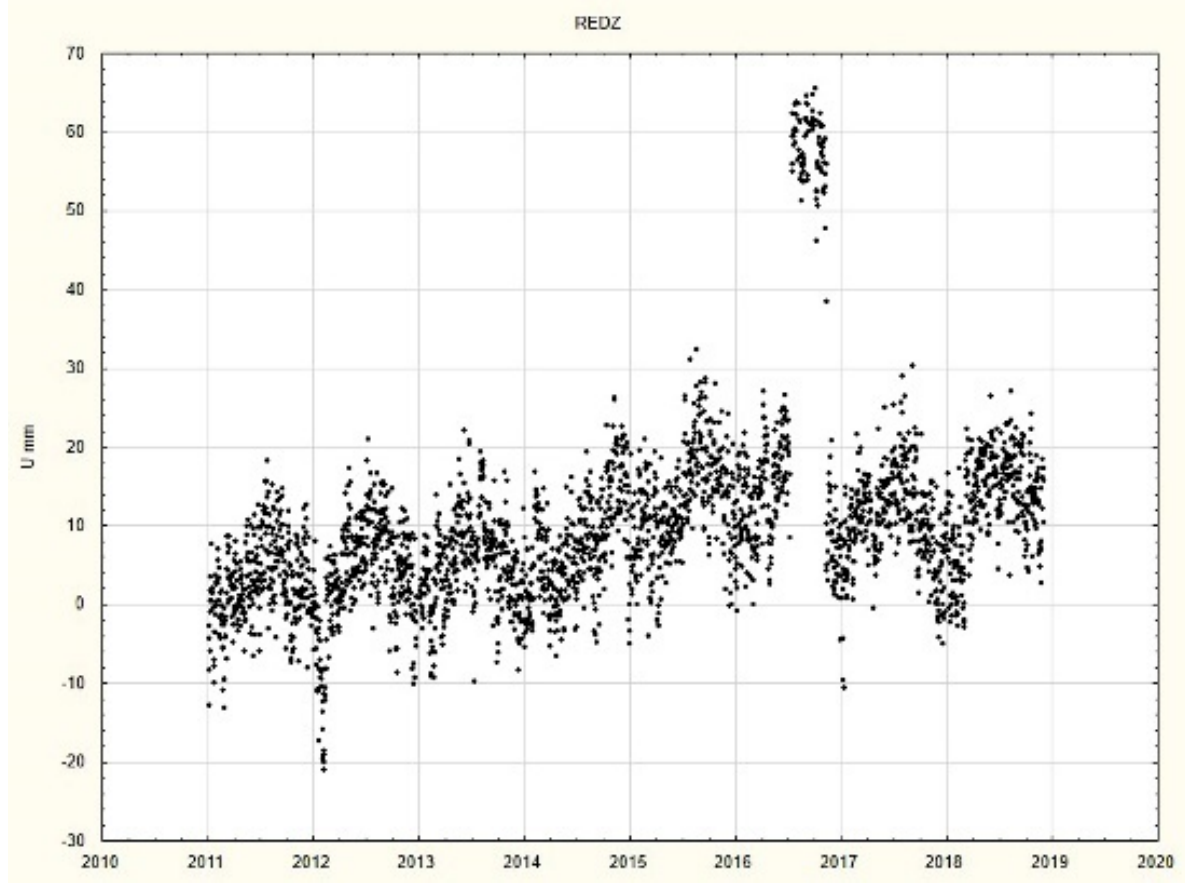

Figure 2. Time series of vertical movement of the Redzikow o station with all observations from each day

The calculated time series and their analysis should be independent of the team that performs the calculations. To verify this hypothesis, calculations were made in the third version. Therefore, we computed the third case which is equivalent to the second (all observations) but calculated independently by the Military University of Aviation (MUA) team. 
The emergence of multiple satellite navigation systems, including BDS, Galileo, modernized GPS, and GLONASS, brings great opportunities and challenges for PPP. Thus, we decided to compute the fourth case time series for selected permanent stations using multi-GNSS observation and assess their impact on the accuracy of estimated parameters.

\subsection{Time se ries analys is}

Typically, time series analysis includes outlier detection, offsets and displacements identification, noise characterization, trend and seasonal signals estimation, and residual analysis (Robinson, 2009; Fulcher et al., 2013; Herff and Krusienski, 2018). The most popular analysis tools are GGMatlab (Herring, 2003), FODITS (Tian, 2011), and CATS (Williams, 2011). In our work, we used module statFit.py from the GipsyX software.

The positions from the daily GPS observations for each station for variants 1, 2, and 3 were computed using the gd2e.py module. From the daily solutions (gdcov files), time series files (gdcat) were created using the netSplit.py module for each station. The resulting time series files (gdcat) were analyzed due to spikes and gross errors using the statFit.py module. This module also allows to estimate velocities and seasonal terms for a single site.

\section{VELOCITIES ESTIMATION}

Discontinuities in time series were detected and removed first. They are caused mainly by a change in the antenna reference point while sudden tectonic vibrations have a secondary effect. Detection of jumps in the observation series is an ambitious undertaking and staBreak.py module from GipsyX package was implemented in our case.

Then the outliers were removed. For this purpose, a linear trend and seasonal changes (annual and semi-annual) were calculated, which were deducted from the observed volumes, giving time series of residual observations. Residual observations exceeding the triple value of standard deviation were considered erroneous observations and were removed from the time series.

As a first step, the first two versions will be analyzed and compared, and then the third variant will be discussed.

The results of the calculation, that is, changes in station position for two variants of time series together with the characteristics of their accuracy are given in Tables 1 and 2. 
Table 1. First variant (Koszalin University of Technology). Horizontal and vertical movements of the stations and their accuracy estimation in mm/yr. Reference frame ITRF2014 (IGS14)

\begin{tabular}{|c|l|c|c|c|c|c|c|}
\cline { 2 - 8 } \multicolumn{2}{l|}{} & \multicolumn{2}{c|}{$\mathbf{V}_{\mathbf{n}}$} & \multicolumn{2}{c|}{$\mathbf{V}_{\mathbf{e}}$} & \multicolumn{2}{c|}{$\mathbf{V u}_{\mathbf{u}}$} \\
\hline 1 & Borowa G. & 14.4 & \pm 0.05 & 21.1 & \pm 0.03 & 0.0 & \pm 0.14 \\
\hline 2 & Borowiec & 14.8 & \pm 0.06 & 20.3 & \pm 0.04 & +0.3 & \pm 0.18 \\
\hline 3 & Biała Pod. & 14.2 & \pm 0.04 & 21.6 & \pm 0.03 & -0.2 & \pm 0.11 \\
\hline 4 & Bydgoszcz & 15.0 & \pm 0.08 & 19.9 & \pm 0.06 & -0.1 & \pm 0.22 \\
\hline 5 & Gorzów Wlk & 14.97 & \pm 0.08 & 19.6 & \pm 0.06 & -0.3 & \pm 0.23 \\
\hline 6 & Józefosław & 14.2 & \pm 0.04 & 20.9 & 0.03 & -0.6 & \pm 0.11 \\
\hline 7 & Katowice & 11.4 & \pm 0.04 & 21.1 & \pm 0.03 & -2.1 & \pm 0.11 \\
\hline 8 & Kraków & 14.6 & \pm 0.05 & 21.4 & \pm 0.04 & -0.7 & \pm 0.15 \\
\hline 9 & Lamkówko & 14.5 & \pm 0.05 & 20.2 & \pm 0.04 & 0.0 & \pm 0.15 \\
\hline 10 & Łódź & 14.6 & \pm 0.04 & 20.7 & \pm 0.03 & 0.8 & \pm 0.11 \\
\hline 11 & Redzikowo & 15.2 & \pm 0.15 & 18.8 & 0.13 & 4.0 & \pm 0.49 \\
\hline 12 & Suwałki & 13.9 & \pm 0.08 & 20.6 & \pm 0.06 & -0.6 & \pm 0.23 \\
\hline 13 & Ustrzyki Dln. & 14.1 & \pm 0.08 & 21.8 & \pm 0.06 & -0.4 & \pm 0.25 \\
\hline 14 & Wrocław & 15.8 & \pm 0.06 & 20.1 & \pm 0.04 & -0.7 & \pm 0.16 \\
\hline 15 & Żywiec & 14.8 & \pm 0.08 & 21.0 & \pm 0.03 & 1.0 & 0.11 \\
\hline
\end{tabular}

Table 2. Sec ond variant (University of Warmia and Mazury). Horizontal and vertical movements of the stations and their accuracy estimation in mm/yr. Reference frame ITRF2014 (IGS14)

\begin{tabular}{|c|l|c|c|c|c|c|c|}
\cline { 2 - 8 } \multicolumn{2}{c}{} & \multicolumn{2}{c|}{$\mathbf{V n}$} & \multicolumn{2}{c|}{$\mathbf{v e}^{\mathbf{2}}$} & \multicolumn{2}{c|}{$\mathbf{v u}^{\mathbf{n}}$} \\
\hline 1 & Borowa G. & 14.5 & \pm 0.01 & 21.1 & \pm 0.00 & 0.1 & \pm 0.03 \\
\hline 2 & Borowiec & 14.7 & \pm 0.01 & 20.3 & \pm 0.01 & 0.0 & \pm 0.02 \\
\hline 3 & Biała Pod. & 14.2 & \pm 0.01 & 21.6 & \pm 0.01 & 0.0 & \pm 0.02 \\
\hline 4 & Bydgoszcz & 14.8 & \pm 0.01 & 20.0 & \pm 0.01 & -0.3 & \pm 0.04 \\
\hline 5 & Gorzów Wlk & 15.1 & \pm 0.01 & 19.5 & \pm 0.01 & 0.0 & \pm 0.04 \\
\hline 6 & Józefosław & 14.2 & \pm 0.01 & 20.9 & \pm 0.00 & -0.5 & \pm 0.02 \\
\hline 7 & Katowice & 11.3 & \pm 0.01 & 21.1 & \pm 0.00 & -1.9 & \pm 0.02 \\
\hline 8 & Kraków & 14.6 & \pm 0.01 & 21.5 & \pm 0.01 & -0.6 & \pm 0.03 \\
\hline 9 & Lamkówko & 14.5 & \pm 0.01 & 20.2 & \pm 0.01 & 0.2 & \pm 0.03 \\
\hline 10 & Łódź & 14.6 & \pm 0.01 & 20.7 & \pm 0.00 & 0.8 & \pm 0.02 \\
\hline 11 & Redzikowo & 14.4 & \pm 0.02 & 19.5 & \pm 0.01 & 1.0 & \pm 0.06 \\
\hline 12 & Suwałki & 14.0 & \pm 0.02 & 20.7 & \pm 0.01 & -0.5 & \pm 0.04 \\
\hline 13 & Ustrzyki Dln. & 14.2 & \pm 0.02 & 21.9 & \pm 0.01 & -0.2 & \pm 0.04 \\
\hline 14 & Wrocław & 15.7 & \pm 0.01 & 20.2 & \pm 0.01 & -0.3 & \pm 0.03 \\
\hline 15 & Żywiec & 14.8 & \pm 0.02 & 21.4 & \pm 0.01 & 0.2 & \pm 0.04 \\
\hline
\end{tabular}

\subsection{Cross-comparison of the first two versions}

Then, the linear trend of the first two versions of the time series was compared. For this purpose, the differences were calculated by subtracted values $\left(\mathrm{v}_{\mathrm{n}}, \mathrm{v}_{\mathrm{e}}, \mathrm{v}_{\mathrm{u}}\right)$ of the second variant 
from the values $\left(\mathrm{v}_{\mathrm{n}}, \mathrm{v}_{\mathrm{e}}, \mathrm{v}_{\mathrm{u}}\right)$ calculated in the first variant. The results of the differences are presented in Figure 3. Differences in component $\mathrm{v}_{\mathrm{n}}$ are from -0.1 to $+0.1 \mathrm{~mm} / \mathrm{yr}$, except for Redzikowo station $(+0.8 \mathrm{~mm} / \mathrm{yr})$. The differences in the component $\mathrm{v}_{\mathrm{e}}$ are from -0.1 to 0.2 $\mathrm{mm} / \mathrm{yr}$, except for Redzikowo $(-0.7 \mathrm{~mm} / \mathrm{yr})$ and Żywiec $(-0.4 \mathrm{~mm} / \mathrm{yr})$, while the differences in the component $\mathrm{v}_{\mathrm{u}}$ are from -0.3 to $+0.3 \mathrm{~mm} / \mathrm{yr}$, except for Redzikowo station $(+3.0 \mathrm{~mm} / \mathrm{yr})$ and Żywiec station $(+0.8 \mathrm{~mm})$.

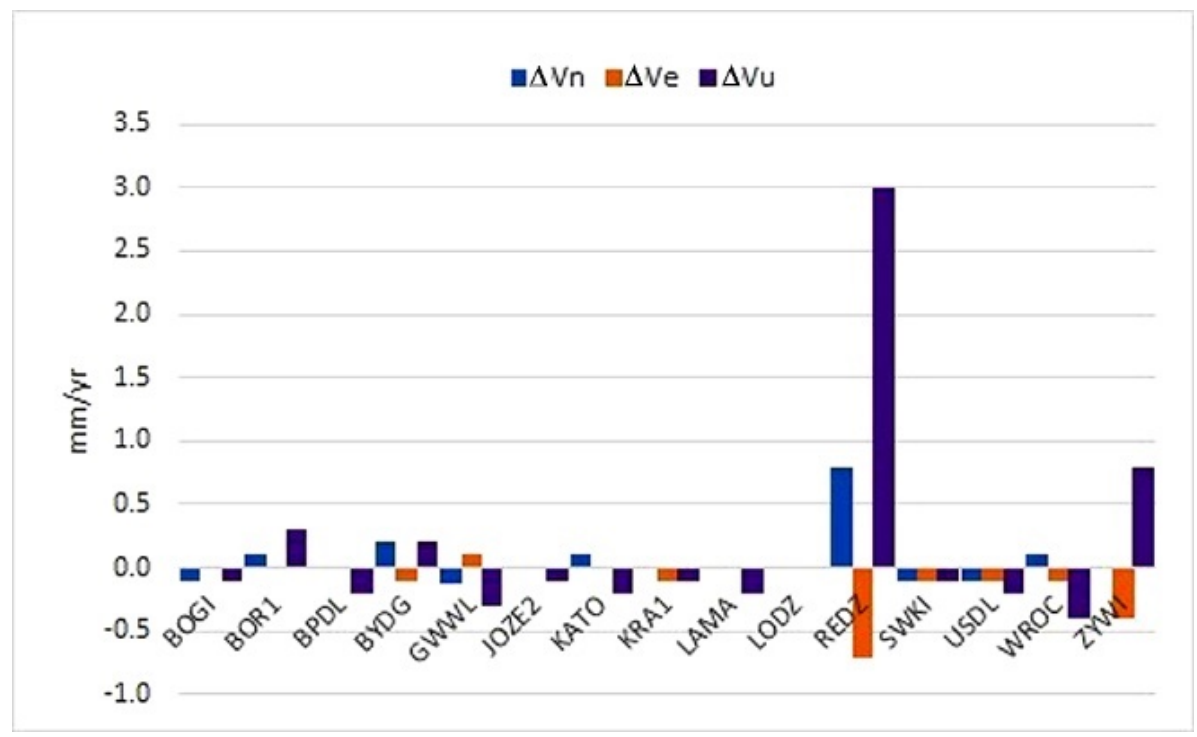

Figure 3. Differences in the horizontal and vertical components computed in the first and second variants

The comparison shows that the largest differences occur in the component $\mathrm{v}_{\mathrm{u}}$. To clarify these discrepancies for Redzikowo station, the time series of the component shown in Figure 41 were re-examined. The analysis shows that the first version does not describe the phenomenon studied very accurately (no clear strokes and discontinuities), resulting in a poor estimation of the components $\mathrm{v}_{\mathrm{n}}, \mathrm{v}_{\mathrm{e}}$, and $\mathrm{v}_{\mathrm{u}}$. According to the analysis, only all daily solutions should be taken to estimate the changes in station position properly.

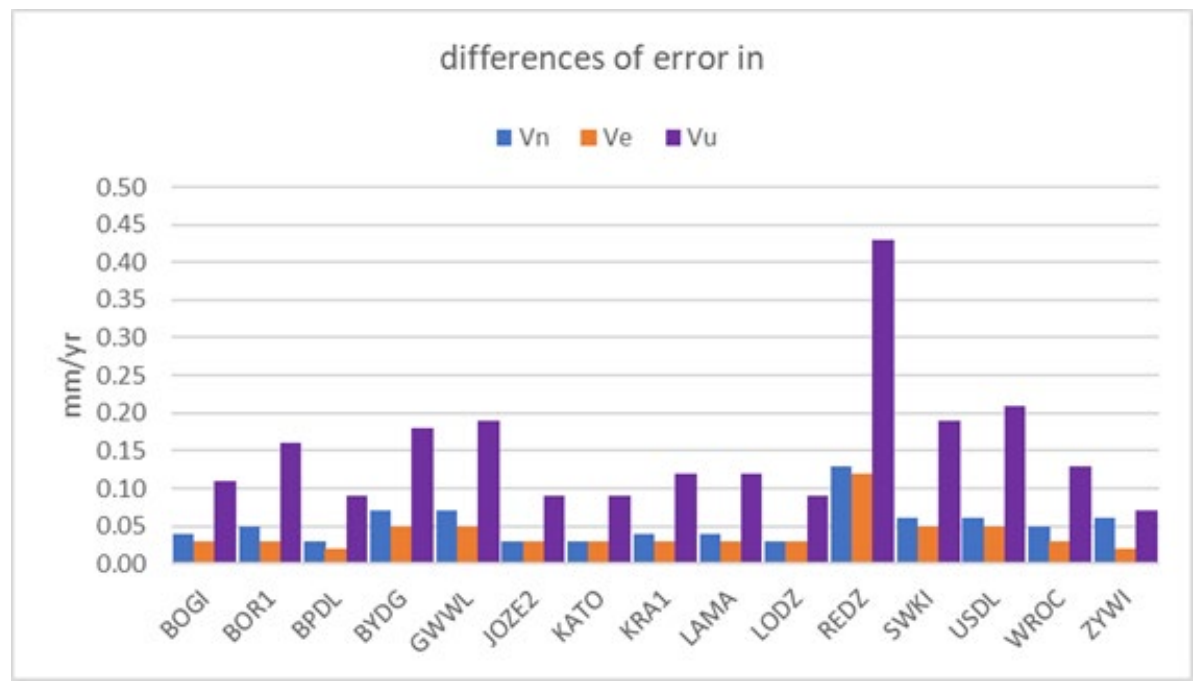

Figure 4. Differences in mean square errors computed in the first and second variants

Figure 4 shows the error differences of the mean square errors of components $v_{n}, v_{e}, v_{u}$ calculated from the first two sets of time series. The comparison shows that the errors of 
components $\mathrm{v}_{\mathrm{n}}, \mathrm{v}_{\mathrm{e}}$, and $\mathrm{v}_{\mathrm{u}}$ calculated for all daily observations in the years 2011-2018 are of the order of $0.01 \mathrm{~mm} / \mathrm{yr}$, while the errors calculated in the first set of time series are about 0.1 $\mathrm{mm} / \mathrm{yr}$, which are almost 10 times greater. The comparison shows that all daily observations over the 8 years considered should be taken to accurately determine the movements of GNSS stations. Observations from a series of 8 years ensure that changes in the Earth's crust are computed with a satisfactory accuracy of approximately $0.01 \mathrm{~mm} / \mathrm{yr}$.

Later in the work, it was decided to compare the components $\mathrm{v}_{\mathrm{n}}, \mathrm{v}_{\mathrm{e}}, \mathrm{v}_{\mathrm{u}}$ computed in this work, version two, with the results obtained by the EPN center. In 2001, a special EPN project Coordinate Time Series Analysis (TSA_SP) was launched. The main task of the project was to monitor the analysis of the weekly series of combined SINEX EPN solutions to further improve the quality of EPN products. Routine monitoring involves cleaning the time series of individual station coordinates and recording and publishing detected spikes and errors of thick coordinates. This information was also used to calculate the ITRF2005 reference frame and its regional density. Estimated coordinates and speeds, along with outliers and data spikes, were regularly updated and published on the EPN CB website.

Following Resolution 1 of the EUREF 2008 symposium in Brussels, the time series analysis project has been integrated into routine EPN operations. In Table 3 are given station movements in horizontal and vertical directions and their error estimation calculated in the EPN analysis center.

Table 3. EPN solution from the analysis center. Velocities and their accuracy (in $\mathrm{mm} / \mathrm{yr}$ ) of permanent stations in Poland in ITRF2014 (IGS14)

\begin{tabular}{|c|c|c|c|c|c|c|c|c|}
\cline { 2 - 8 } \multicolumn{2}{c|}{} & Years & $\mathbf{v}_{\mathbf{n}}$ & $\sigma_{\mathbf{n}}$ & $\mathbf{v}_{\mathbf{e}}$ & $\sigma_{\mathbf{e}}$ & $\mathbf{v}_{\mathbf{u}}$ & $\sigma_{\mathbf{u}}$ \\
\hline 1 & Borowa G. & $2001-2019$ & 14.4 & \pm 0.01 & 20.8 & \pm 0.01 & -0.2 & \pm 0.03 \\
\hline 2 & Borowiec & $1995-2019$ & 14.8 & \pm 0.00 & 20.1 & \pm 0.00 & -0.4 & \pm 0.00 \\
\hline 3 & Bydgoszcz & $2008-2019$ & 14.7 & \pm 0.01 & 20.0 & \pm 0.01 & -0.3 & \pm 0.04 \\
\hline 4 & Gorzów Wlk & $2008-2019$ & 15.0 & \pm 0.01 & 19.5 & \pm 0.01 & -1.1 & \pm 0.04 \\
\hline 5 & Józefosław & $1995-2019$ & 14.2 & \pm 0.00 & 20.9 & \pm 0.00 & -0.2 & \pm 0.01 \\
\hline 6 & Katowice & $2003-2019$ & 11.2 & \pm 0.01 & 21.4 & \pm 0.01 & -1.3 & \pm 0.04 \\
\hline 7 & Kraków & $2010-2019$ & 14.5 & \pm 0.00 & 21.2 & \pm 0.00 & 0.1 & \pm 0.01 \\
\hline 8 & Lamkówko & $1996-2019$ & 14.4 & \pm 0.01 & 20.3 & \pm 0.00 & -0.1 & \pm 0.02 \\
\hline 9 & Lódź & $2008-2019$ & 14.6 & \pm 0.01 & 20.9 & \pm 0.01 & -0.6 & \pm 0.03 \\
\hline 10 & Redzikowo & $2008-2019$ & 15.5 & \pm 0.01 & 19.6 & \pm 0.01 & 0.3 & \pm 0.04 \\
\hline 11 & Suwałki & $2008-2019$ & 14.0 & \pm 0.01 & 20.4 & \pm 0.01 & -0.8 & \pm 0.03 \\
\hline 12 & Ustrzyki Dln. & $2008-2019$ & 14.2 & \pm 0.01 & 21.9 & \pm 0.01 & -0.4 & \pm 0.04 \\
\hline 13 & Wrocław & $1997-2019$ & 15.0 & \pm 0.01 & 20.1 & \pm 0.01 & 0.1 & \pm 0.02 \\
\hline 15 & Żywiec & $2003-2019$ & 15.0 & \pm 0.01 & 21.2 & \pm 0.01 & 0.0 & \pm 0.04 \\
\hline
\end{tabular}

The next comparison of the horizontal and vertical movements calculated in the second version with similar movements developed by the EPN analysis center was made.

A graphic illustration of this comparison is presented in Table 3 and Figures 5 and 6 . The comparison shows that, in the case of component $\mathrm{v}_{\mathrm{n}}$, the differences are of the order of 0.1 $\mathrm{mm} / \mathrm{yr}$, except for Redzikowo where the component vn differs by $1.1 \mathrm{~mm} / \mathrm{yr}$. For component $\mathrm{v}_{\mathrm{e}}$, the differences are -0.3 to $+0.3 \mathrm{~mm} / \mathrm{yr}$. In the case of component $\mathrm{v}_{\mathrm{u}}$, the biggest 
differences occur at the stations Gorzów Wlk. $-1.1 \mathrm{~mm} / \mathrm{yr}$ and Lodz $-1.4 \mathrm{~mm} / \mathrm{yr}$. Error differences of all components are within $0.02 \mathrm{~mm} / \mathrm{yr}$, which can be considered fairly good conformity of the accuracy assessment carried out.

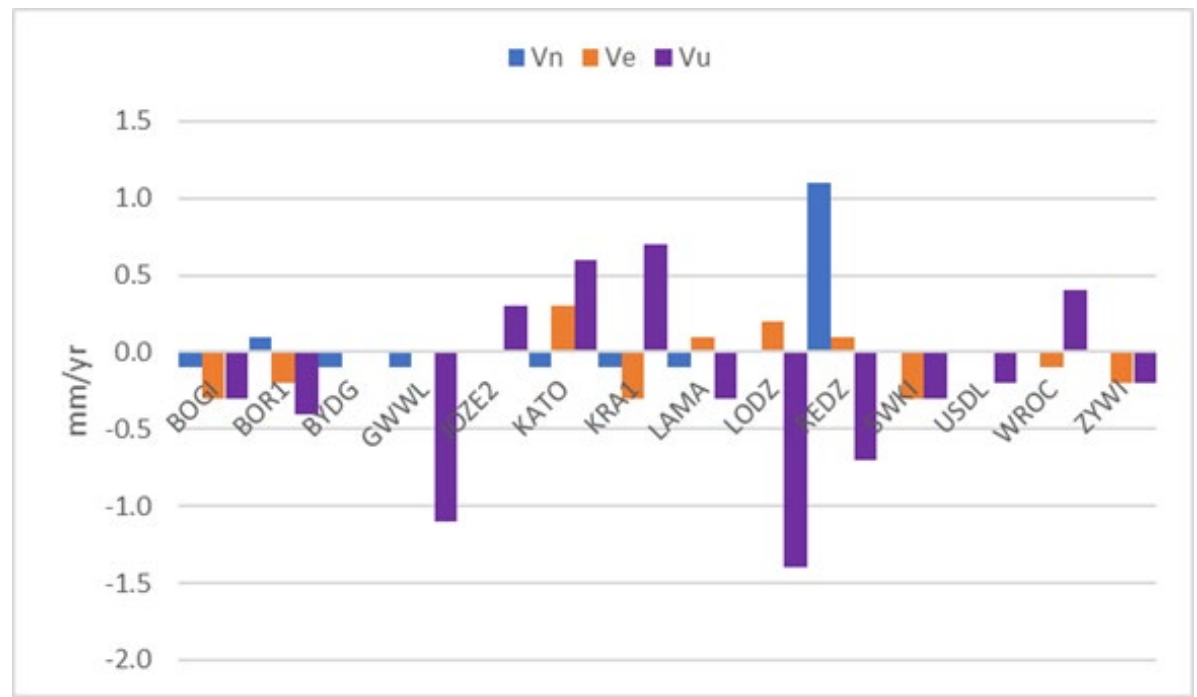

Figure 5. Comparison of horizontal and vertical movements computed by EPN and in the second variant

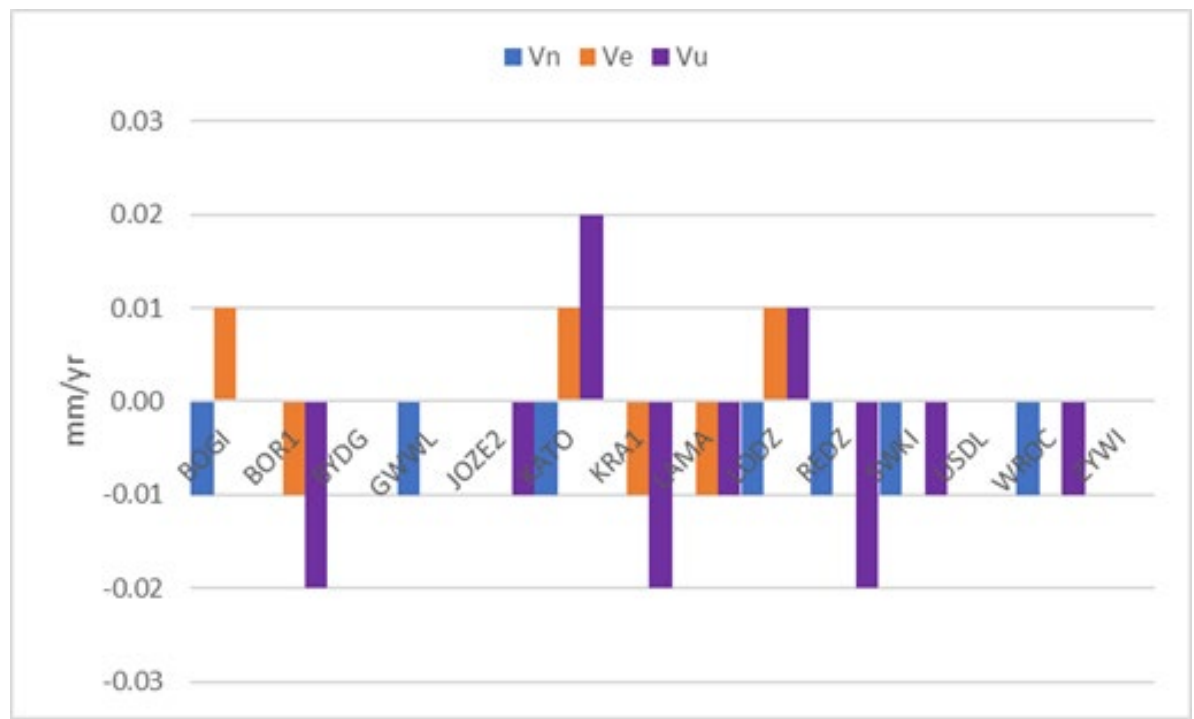

Figure 6. Comparison of the mean square error computed by the EPN and in the second variant

\subsection{The third variant}

The third variant was calculated by the team of the MUA in Dęblin. The results of processing daily GNSS observations are for the period 2011-2018 by GipsyX software. As a result, many new files were created, among which station series is the most important for analysis. The resulting time series (gdcat) were analyzed due to spikes and gross errors using the statFit.py module. The results are shown in Table 4 and show a pretty good agreement with the NASA JPL laboratory data (individual IGS stations) and EPN data. However, for some stations, there are significant differences that could be caused by different processing methods and the mathematical interpretation of the final results. Most significant is this dependence on the vertical component. 
Table 4. Third variant, horizontal and vertical movements and their accuracy estimation for all stations by GipsyX ( $\mathrm{mm} / \mathrm{yr}$ )

\begin{tabular}{|c|c|c|c|c|c|c|c|}
\cline { 3 - 8 } \multicolumn{2}{c|}{} & $\mathbf{V}_{\mathbf{n}}$ & $\mathbf{v}_{\mathbf{e}}$ & $\mathbf{v}_{\mathbf{u}}$ & $\sigma_{\mathbf{n}}$ & $\sigma_{\mathbf{e}}$ & $\sigma_{\mathbf{u}}$ \\
\hline 1 & Borowa G. & 14.5 & 21.1 & 0.1 & \pm 0.05 & \pm 0.04 & \pm 0.26 \\
\hline 2 & Borowiec & 14.0 & 20.0 & 0.4 & \pm 0.21 & \pm 0.09 & \pm 0.12 \\
\hline 3 & Bydgoszcz & 14.2 & 21.6 & -0.1 & \pm 0.07 & \pm 0.09 & \pm 0.16 \\
\hline 4 & Gorzów Wlk & 14.9 & 19.8 & 2.0 & \pm 0.08 & \pm 0.06 & \pm 0.49 \\
\hline 5 & Józefosław & 15.3 & 19.8 & 3.7 & \pm 0.09 & \pm 0.08 & \pm 0.72 \\
\hline 6 & Katowice & 14.2 & 20.8 & -0.4 & \pm 0.07 & \pm 0.05 & \pm 0.14 \\
\hline 7 & Kraków & 11.3 & 21.1 & -1.9 & \pm 0.08 & \pm 0.07 & \pm 0.18 \\
\hline 8 & Lamkówko & 14.6 & 21.5 & -0.6 & \pm 0.08 & \pm 0.06 & \pm 0.21 \\
\hline 9 & Lódź & 14.5 & 20.2 & 0.3 & \pm 0.08 & \pm 0.03 & \pm 0.24 \\
\hline 10 & Redzikowo & 14.6 & 20.7 & 0.9 & \pm 0.08 & \pm 0.06 & \pm 0.23 \\
\hline 11 & Suwałki & 15.2 & 19.3 & 2.1 & \pm 0.11 & \pm 0.08 & \pm 0.65 \\
\hline 12 & Ustrzyki Dln. & 14.9 & 20.8 & -0.6 & \pm 0.17 & \pm 0.04 & \pm 0.15 \\
\hline 13 & Wrocław & 14.3 & 21.3 & 1.9 & \pm 0.07 & \pm 0.13 & \pm 0.36 \\
\hline 15 & Żywiec & 15.5 & 20.2 & -1.2 & \pm 0.12 & \pm 0.05 & \pm 0.31 \\
\hline
\end{tabular}

The obtained results were also analyzed using the iGPS software package (Tian, 2011). For analysis of the coordinate time series of the selected stations, the parameters of the semiannual/annual trend were determined on the iGPS charting panel. Any nonlinear offsets in the time series were removed from processing. In the time series of individual stations (Bydgoszcz, Gorzów Wlk., Łódź, Redzikowo, Ustrzyki Dolne, Suwałki, Wrocław, Żywiec), significant deviations of coordinates from the average values were found (see, e.g. the $v_{u}$ component for the Gorzów Wlk. station (Figure 7), which were later removed from processing.

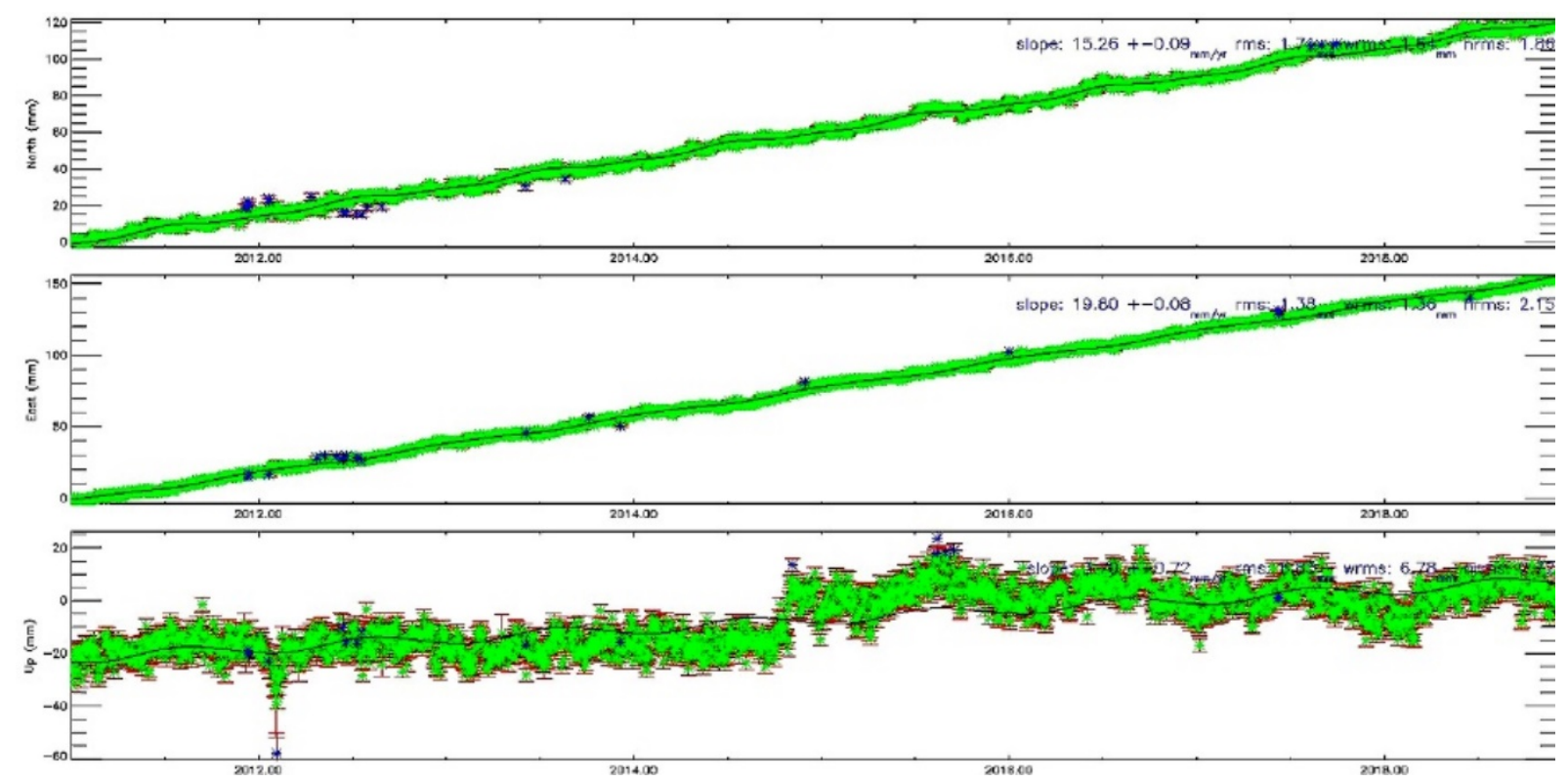

Figure 7. Coordinate time series in iGPS 
The iGPS program automatically determines and plots the value of the RMS error for each coordinate component. To estimate the linear velocity, annual and semi-annual amplitudes, the Model utility is used. If there are any undetected offsets and shifts in the graphs after using this utility, we can easily find them by looking at the remaining graphs of the time series. After that, they can be additionally determined and deleted manually using the Offset Selector utility and reused by the Model utility.

Based on the results of the analysis of all the above stations, the value of the RMS error after processing, a coordinate time series in GipsyX and the iGPS software was obtained. Table 5 shows the quantitative characteristics of this analysis and comparison with the values given in Table 4.

Table 5. Comparative characteristics of the processing results of the coordinate time series of individual stations by iGPS softw are and GipsyX ( $\mathrm{mm} / \mathrm{yr})$

\begin{tabular}{|c|c|c|c|c|c|c|}
\cline { 2 - 7 } \multicolumn{1}{c|}{} & $\mathbf{V}_{\mathbf{n}}$ & $\mathbf{v}_{\mathbf{e}}$ & $\mathbf{v}_{\mathbf{u}}$ & $\sigma_{\mathbf{n}}$ & $\sigma_{\mathbf{e}}$ & $\sigma_{\mathbf{u}}$ \\
\hline BYDG_iGPS & 15.0 & 20.2 & -0.6 & \pm 0.07 & \pm 0.09 & \pm 0.45 \\
\hline BYDG_Gipsy & 14.9 & 19.8 & 2.0 & \pm 0.08 & \pm 0.06 & \pm 0.49 \\
\hline GWWL_iGPS & 15.3 & 19.4 & -0.5 & \pm 0.22 & \pm 0.16 & \pm 0.41 \\
\hline GWWL_Gipsy & 15.3 & 19.8 & 3.7 & \pm 0.09 & \pm 0.08 & \pm 0.72 \\
\hline LODZ_iGPS & 14.4 & 21.1 & -0.1 & \pm 0.10 & \pm 0.10 & \pm 0.22 \\
\hline LODZ_Gipsy & 14.6 & 20.7 & 0.9 & \pm 0.08 & \pm 0.06 & \pm 0.23 \\
\hline REDZ_iGPS & 15.5 & 19.4 & 0.1 & \pm 0.10 & \pm 0.08 & \pm 0.35 \\
\hline REDZ_Gipsy & 15.2 & 19.3 & 2.1 & \pm 0.11 & \pm 0.08 & \pm 0.65 \\
\hline USDL_iGPS & 14.5 & 21.8 & 0.1 & \pm 0.09 & \pm 0.08 & \pm 0.35 \\
\hline USDL_Gipsy & 14.3 & 21.3 & 1.9 & \pm 0.07 & \pm 0.13 & \pm 0.36 \\
\hline WROC_iGPS & 15.7 & 20.2 & -0.2 & \pm 0.09 & \pm 0.08 & \pm 0.17 \\
\hline WROC_Gipsy & 15.5 & 20.2 & -1.2 & \pm 0.12 & \pm 0.05 & \pm 0.31 \\
\hline ZYWI_iGPS & 15.0 & 21.4 & 0.3 & \pm 0.11 & \pm 0.08 & \pm 0.31 \\
\hline ZYWI_Gipsy & 14.8 & 21.0 & 1.3 & \pm 0.08 & \pm 0.08 & \pm 0.21 \\
\hline
\end{tabular}

As shown in Table 5, the height components of the coordinates have undergone significant changes, especially for stations such as Bydgoszcz, Gorzów Wlk., Redzikowo, and Ustrzyki Dolne. The efficiency of using an additional software package for the analysis of coordinate time series in our case is relatively high. This can be due to both a sufficiently significant ( 8 years) observation interval and a high level of accuracy of processing GNSS observations with the GipsyX software package.

\subsection{The combination of multi-GNSS observations}

The emergence of multiple satellite navigation systems, including BDS, Galileo, modernized GPS, and GLONASS, brings great opportunities and challenges for PPP.

To assess the impact of additional GNSS observations on the accuracy of the horizontal and vertical movements of Earth's crust, 18 GNSS stations were selected in different countries of Europe by the MUA team (Khoptar and Savchuk, 2020). The observation period covered a little more than 2 years (from 08.13.2017 to 12.31.2019). The choice of stations and the processing period were determined by the presence of IGS MGEX products from CODE, as well as the corresponding multi-GNSS observation files in the RINEX 3 format. These 
observations were processed by GipsyX in five scenarios, which differed from each other by a combination of navigation systems and products (№ scenario, products, GNSS). In total, we obtained for each station, 640 values of coordinates for each of the five scenarios (№1, JPL, GPS; №2, CODE, GPS; №3, CODE, GPS+GLONASS; №4, CODE, GPS+GLONASS+Galileo; №5, CODE, GPS+GLONASS+Galileo+BeiDou). This made it possible to generalize the obtained coordinate velocities and their estimates. For example, Table 6 shows the results obtained for the GNSS station BOR1, which is located near Poznan. It shows a very good agreement with NASA's JPL laboratory data (see JPL values in Table 6) which are the results taken from the JPL solutions for the station BOR1 for all years of its activity (over 20 years). For us, they were control data. As can be seen from this table, our $\mathrm{G}+\mathrm{R}+\mathrm{E}+\mathrm{C} / \mathrm{CODE}$ scenario is the closest to the long-term solution of JPL.

Table 6. The average coordinates velocities and their estimate for the station BOR1

\begin{tabular}{|c|c|c|c|c|c|c|}
\hline \multirow{2}{*}{$\begin{array}{c}\text { Scenario / } \\
\text { products }\end{array}$} & \multicolumn{3}{|c|}{ Velocities $(\mathbf{m m} / \mathbf{y r})$} & \multicolumn{3}{c|}{ Accuracy $(\mathbf{m m} / \mathbf{y r})$} \\
\cline { 2 - 7 } & $\mathbf{V}_{\mathbf{e}}$ & $\mathbf{v}_{\mathbf{n}}$ & $\mathbf{v}_{\mathbf{u}}$ & $\sigma_{\mathbf{e}}$ & $\sigma_{\mathbf{n}}$ & $\sigma_{\mathbf{u}}$ \\
\hline $\mathrm{G} / \mathrm{JPL}$ & 20.412 & 14.076 & 0.701 & 0.089 & 0.054 & 0.152 \\
\hline $\mathrm{G} / \mathrm{CODE}$ & 20.406 & 14.655 & -2.129 & 0.089 & 0.054 & 0.152 \\
\hline $\mathrm{G}+\mathrm{R} / \mathrm{CODE}$ & 20.261 & 14.986 & -2.393 & 0.059 & 0.038 & 0.112 \\
\hline $\mathrm{G}+\mathrm{R}+\mathrm{E} / \mathrm{CODE}$ & 20.001 & 14.998 & -0.253 & 0.051 & 0.033 & 0.096 \\
\hline $\mathrm{G}+\mathrm{R}+\mathrm{E}+\mathrm{C} / \mathrm{CODE}$ & 20.002 & 14.998 & -0.253 & 0.051 & 0.033 & 0.096 \\
\hline JPL value & 20.091 & 14.713 & -0.417 & 0.032 & 0.045 & 0.130 \\
\hline
\end{tabular}

So, it can be argued that the results of processing GNSS observations based on multi-GNSS observations show submillimeter accuracy in determining the coordinates of stations even at a relatively small time interval. This means that the results obtained during multi-GNSS PPP processing can be used for further estimation of geodynamic processes.

\section{CONCLUSIONS}

In our computation, we used the GipsyX suite of programs designed for the processing of GNSS data from ground stations and satellites. The new GipsyX software is a robust and efficient tool for geodetic data analysis and simulations.

Using about 8 years of continuous data from the Polish GNSS stations, we analyzed the daily GPS solutions to determine secular horizontal and vertical movements. We performed few tests. In the first case, we used two data sets: the first one containing one daily observation per month and the second one containing all daily observations for the whole period of 8 years. Our results have shown that only all daily solutions give secular trends with an appropriate accuracy of $0.01 \mathrm{~mm} / \mathrm{yr}$, and such time series were analyzed in our further works.

The daily solutions for 8 years computed at UWM were compared with the EPN solutions. Our results suggest that there are small differences in horizontal and vertical velocities and mean square error. At some stations, for example, Łódź, the differences are much larger and reach $1.4 \mathrm{~mm} / \mathrm{yr}$. The differences in mean square errors are within $0.02 \mathrm{~mm} / \mathrm{yr}$, which can be considered fairly good compliance with the accuracy assessment carried out.

The horizontal and vertical movements calculated for the third variant by the LAW team show very small discrepancies with the second case (UWM) and EPN solution, except for the station BYDG, where the differences are significant. 
The impact of additional GNSS observations on the accuracy of determination of horizontal and vertical movements of the Earth's crust was also assessed. It showed a submillimeter accuracy in computed coordinates of stations even at a relatively small time interval. It means that multi-GNSS PPP processing can be used in the future for the estimation of geodynamic processes.

So, it can be argued that the results of processing GNSS observations based on multi-GNSS observations show submillimeter accuracy in determining the coordinates of stations even at a relatively small time interval. This means that the results obtained during multi-GNSS PPP processing can be used for further estimation of geodynamic processes. Finally, we have shown that there are slight differences that can affect geodynamic interpretation, and more research is needed to clarify the details of this process.

Acknowledgments. The authors thank the Main Office of Surveying and Cartography for the ASG GPS data and the California Institute of Technology for license to a binary version of GipsyX software.

\section{REFERENCES}

Altamimi Z., Rebischung P., Métivier L., Collilieux X. (2016) ITRF2014: A new release of the International Terrestrial Reference Frame modeling nonlinear station motions, Journal of Geophysical Research: Solid Earth, Vol. 121, No. 8, 6109-6131.

Altamimi Z., Sillard P., Boucher C. (2007) CATREF software: Combination and analysis of terrestrial reference frames, LAREG Technical, Institut Géographique National, Paris, France, p. 47.

Blewitt G. (2011) Advances in Global Positioning System technology for geodynamics investigations, Wiley

Bock Y., Fang Peng., Genrich J., Hager B., Herring T., Hudnut K. (1993) Detection of crustal deformation from the Landers earthquake sequence using continuous geodetic measurements, Nature, Vol. 361, No. 6410, 337-340

Bosy J., Graszka W., Oruba A. (2010) ASG-EUPOS i podstawowa osnowa geodezyjna w Polsce, Biuletyn Wojskowej Akademii Technicznej, Vol. 59, 7-15.

Bosy J., Krynski J. (2015) Reference frames and reference networks, Geodesy and Cartography, Vol. 64, No. 2, 5-29

Chen J., Yang M. (2011) Absolute site velocity estimation using the GPS precise point positioning technique, in 32nd Asian Conference on Remote Sensing, ACRS 2011, 1443-1448.

Dong Da-Nan. (1989) Global Positioning System network analysis with phase ambiguity resolution applied to crustal deformation studies in California, Journal of Geophysical Research, Vol. 94, No. B4, 3949-3966

Feng J., Chen H. (2019) Time series analysis of Xiamen GPS continuous operating station, Journal of Geomatics, Vol44, No. 5

Fulcher B., Little M., Jones N. (2013) Highly comparative time-series analysis: The empirical structure of time series and their methods, Journal of the Royal Society Interface, Vol.10, No. 83.

Goudarzi M., Banville S. (2018) Application of PPP with ambiguity resolution in earth surface deformation studies: a case study in eastern Canada, Survey Review, Vol. 50, No.363, 531-544 
Gubler E. (1984) The determination of recent crustal movements from precise leveling data, a review, in Workshop on precise leveling, Eds. H. Pelzer and W. Niemeier.

Gubler E., Kahle H. G. (1985) Recent crustal movements in the Alpine-Mediterrane a region analyzed in the Swiss ALPS, Tectonophysics, Vol 130, 1-4

Guo Fei, Li Xingxing, Zhang Xiaohong, Wang Jinling (2017) The contribution of MultiGNSS Experiment (MGEX) to precise point positioning, Advances in Space Research, Vol. 59, No. 11, 2714-2725.

Herff C., Krusienski D. (2018) Extracting features from time series, in Fundamentals of Clinical Data Science. Springer International Publishing, 85-100.

Herring T. (2003) MATLAB Tools for viewing GPS velocities and time series, GPS Solution, No. 7

Hofmann-Wellenhof B., Lichtenegger H., Collins J. (2012) Global positionig System: Theory and Practise. Springer Science \& Business Media

Kontny B. (2012) Models of vertical movements of the earth crust surface in the area of Poland derived from leveling and GNSS data, Acta Geodynamica Et Geomaterialia. Vol. 9, No. 3, 331-337

Khoptar A., Savchuk S. (2020) Estimation of Ionospheric Delay Influence on the Efficiency of Precise Positioning of Multi-GNSS Observations, Baltic Surveying, Vol. 12, 14-18

Kowalczyk K. (2017) Application of PPP Solution to Determine the Absolute Vertical Crustal Movements, in Proceedings of the 10th International Conference, Vilnius Gediminas Technical University.

Kowalczyk K. (2015) Creation of a model of relative vertical crustal movements in the polish territory on the basis of the data from active geodetic network EUPOS (ASG EUPOS), Acta Geodynamica et Geomaterialia, Vol. 12, No. 3, 215-225.

Kowalczyk K. (2005) Determination of land uplift in the area of Poland, 6th International Conference Environment, al Engineering, (May 2005), 903-907.

Kowalczyk K. (2006) Wyznaczenie modelu ruchów pionowych skorupy ziemskiej na obszarze Polski, Praca doktorska, Uniwersytet Warmińsko-Mazurski w Olsztynie

Krakiwsky E., Vanicek P. (1986) Geodesy: The concept. Edited by N. Y. Elsevier.

Heflin B., Hurst K., Muellerschoen R., Wu S., Yunck T, Zumbcrge J. (1996) Gipsy-Oasis II: A High Precision GPS Data Processing System and General Satellite Orbit, NASA Technology Transfer Conference, p. 10.

Lindberg M. (2014) Report from EUREF WG on Deformation models, in Symposium of the IAG Subcommission for Europe (EUREF) held in Vilnius.

Murra J., et al. (2020) Regional global navigation satellite system networks for crustal deformation monitoring, Seismological Research Letters, Vol. 91, No. 2 A, 552-572.

Niewiarowski J., Wwyrzykowski T. (1961) Wyznaczenie współczesnych ruchów pionowych skorupy ziemskiej na obszarze Polski przez porównanie wyników powtarzanych niwelacji precyzyjnych, Prace Instytutu Geodezji i Kartografii, Vol. 7, No. 1.

Pelzer H., Niemeier W. (1984) Precise Levelling, in Contributions to the Workshop on Precise Levelling Held at the University of Hannover, March 16-18, 1983. Ferd. Dümmlers Verlag. 
Robinson G. (2009) Time Series Analysis. International Encyclopedia of Human Geography, 285-293

Ryczywolski M., Oruba A,. Leończyk M. (2008) The precise satellite positioning system ASG-EUPOS, GEOS 2008, January 2007, 1-6

Ryczywolski M., Oruba A., Wajda S. (2010) Coordinate stability monitoring module working within ASG-EUPOS reference station network, EUREF 2010 International Symposium.

Saaranen V. and Mäkinen J. (2002) Determining postglacial rebound from the three precise levellings in Finland: status in 2002, Proceedings of the 14th General Meeting of the Nordic Geodetic Commission, Espoo, Finland, October 1-5,

Sandford H. (1978) Models for Extracting Vertical Crustal Movements Leveling Data, Proc. of the 9th OEOP Conference, An International Symposium on the Applications of Geodesy lo GeoJynamics, Dept. of Geodetic Science Kept. Vol. 2, No. 280, 183-191.

Segall P., Davis J. (1997) GPS applications for geodynamics and earthquake studies, Annual Review of Earth and Planetary Sciences, Vol. 25, 301-336

Szołucha M., Kroszczyński K., Kiliszek D. (2018) Accuracy of Precise Point Positioning (PPP) with the use of different International GNSS Service (IGS) products and stochastic modelling, Geodesy and Cartography, 67(2), 207-238.

Teatini P., Gambolati G., Ferronato M., Settari A., Walters D. (2011) Land uplift due to subsurface fluid injection, Journal of Geodynamics, Vol. 51, No. 1, 1-16

Tian Y. (2011) iGPS: IDL tool package for GPS position time series analysis., GPS Solution, Vol. 15, No. 3, 299-303

Torge W. (2001) Geodesy. 3rd edditi. Berlin, New York: de Gruyter.

Williams S. (2008) CATS: GPS coordinate time series analysis software,GPS Solution, Vol. 12, No. 2, 147-153

Wyrzykowski T. (1985) Mapa współczesnych prędkości pionowych ruchów powierzchni skorupy ziemskiej na obszarze Polski, Instytut Geodezji i kartografii, Warszawa 1895

Wyrzykowski T. (1987) A new determination of recent vertical movements of the earth's crust in Poland, Journal of Geodynamics, Vol. 7, No. 2-4, 171-178

Villiger A., Dach R. (2017) IGS International GNSS Service Technical report 2017, Astronomical Institute University of Bern

Xu G. (2007) Theory, Algorithms and Applications, Springer Science Business Media.

Ye S., R. (2002) Theory and its realization of GPS precise point positioning using undifferenced phase observations Wuhan University, Wuhan,

Yi W., Song W., Lou Y. et al. et al. (2017) Improved method to estimate undifferenced satellite fractional cycle biases using network observations to support PPP ambiguity resolution, GPS Solution, Vol. 21, No. 3, 1369-1378.

Zhang Y., Wu J., Xue Y., Wang Z., Yao Y., Yan X. (2015) Land subsidence and uplift due to long-term groundwater extraction and artificial recharge in Shanghai, China, Hydrogeology Journal, Vol. 23, No. 8, 1851-1866

Zogg J., M. (2002) GPS basics, U-Blox, Thalwil, Vol. No, Januar), 1-60. 
Zumberge J., Heflin M., Jefferson D., Watkins M., Webb F. (1997) Precise point positioning for the efficient and robust analysis of GPS data from large networks, Journal of Geophysical Research: Solid Earth, Vol. 102, No. B3, 5005-5017

Received: 2021-02-03

Reviewed: 2021-06-14 (undisclosed name) and 2021-09-02 (Z. Siejka)

Accepted: 2021-09-24 